\title{
IDENTIFICATION OF THE CARBONATION ZONE IN CONCRETE USING X-RAY MICROTOMOGRAPHY
}

\author{
DARIUSZ ŁYDŻBA, MAGDALENA RAJCZAKOWSKA, DAMIAN STEFANIUK \\ Wrocław University of Technology, Faculty of Civil Engineering, Institute of Geotechnics and Hydrotechnics, \\ Wrocław, Poland, e-mail: dariusz.lydzba@pwr.wroc.pl, \\ magdalena.rajczakowska@pwr.wroc.pl,damian.stefaniuk@pwr.wroc.pl
}

\author{
ANDRZEJ KMITA \\ Wrocław University of Technology, Faculty of Civil Engineering, Institute of Building Engineering, \\ Wybrzeże Wyspiańskiego 27, 50-370 Wrocław, Poland, e-mail: andrzej.kmita@pwr.wroc.pl
}

\begin{abstract}
The article presents an application of X-ray microtomography for identification of the carbonation zone in concrete material. A concrete specimen subjected earlier to harsh environmental conditions is investigated. The material is firstly checked with the use of chemical corrosion indicators and then is subjected to microstructural analysis performed with the use of X-ray microtomography. Two different settings of scanning parameters are applied implying the image resolutions of approximately $14 \mu \mathrm{m}$ per 1 pixel and about $7 \mu \mathrm{m}$ per 1 pixel, respectively. The results obtained are then compared and analyzed. The depth of the carbonation zone is evaluated based on the attenuation curve. The paper highlights also the significance of the corrosion phenomenon in concrete structures. Details of the deterioration mechanisms in concrete are shortly presented.
\end{abstract}

Key words: concrete, carbonation zone, X-ray microtomography

\section{INTRODUCTION}

The processes of degradation of concrete have been an important issue for many years. Better understanding of concrete deterioration makes it possible to design a more durable and resistant to damage material, capable of withstanding different surrounding conditions. Concrete destruction due to nonmechanical loading is usually caused by chemical or physical processes. The most dangerous chemical problems include: leaching of the paste components, carbonation of calcium hydroxide and $\mathrm{C}-\mathrm{S}-\mathrm{H}$, paste deterioration due to exposure to aggressive chemicals such as acids, agricultural sulfates, corrosion of the steel reinforcement, alkali-aggregate reaction. Usually they are combined with physical phenomena such as abrasion, erosion, cavitation, freezing and thawing cycles.

The influence of a harsh environment on concrete can be seen not only on the macro level but also has its impact on the microstructural properties of the material. There are a number of tools that can be ap- plied to characterize and detect the changes in microstructure of concrete due to the deterioration processes. In the case of carbonation, several methods exist that allow different forms of calcium carbonates, portlandite $\mathrm{Ca}(\mathrm{OH})_{2}$ and other chemical compounds to be detected. Villain et al. proposed gamma densimetry and thermogravimetric analysis together with chemical analysis (TGA-CA) to give detailed quantitative profiles of carbonated cementious materials [1]. Lo and Lee used FTIR spectroscopy and detected spectral changes associated with the presence of $\mathrm{Ca}(\mathrm{OH})_{2}$ and morphological transformations of C-H-S [2]. X-ray diffraction analysis (XRDA) was introduced by Chang and Chen, to measure the intensity distribution of $\mathrm{Ca}(\mathrm{OH})_{2}$ and $\mathrm{CaCO}_{3}$ [3]. Nonetheless, all these methods are based on recognition of the chemical compounds of the concrete. This paper presents a method of identification of the carbonation depth using X-ray microtomography and microstructural analysis of concrete with respect to the attenuation curves.

$\mathrm{X}$-ray microtomography has been a useful tool in medicine for decades. In materials science, it is present for a shorter time but it is becoming more and 
more popular, as a non-destructive testing method. It is applied for 3D pore analysis like porosity, pore size distribution and pore geometry as well as 3D grain analysis. Researchers use it to study fractures, mechanical damage of the microstructure, or fluid flow [4].

\section{PRINCIPLES OF X-RAY MICROTOMOGRAPHY}

The term tomography refers to the slice imaging. The X-ray tomography is a system which allows a 3D image to be reconstructed from the $2 \mathrm{D}$ projections obtained by scanning a given object with the X-ray beam. The theoretical background of Computed Tomography (CT) was proposed by the Austrian mathematician Johan Radon in 1917 [5]. He claimed and proved that it is possible to reconstruct an $n$-dimensional object from its $(n-1)$-dimensional projections. Mathematical basis for the image reconstruction was presented 50 years later in two papers by Allan M. Cormack [6], [7]. The first CT scanner was invented in 1972 by Godfrey N. Hounsfield, who was an English electrical engineer [8]. Even though, scanning and reconstruction processes were really time-consuming, the invention became a great success and started being widely used for medical purposes. It happened to be of such significance that Cormack and Hounsfield were awarded the Nobel Prize in Physiology or Medicine in 1979.

The standard X-ray microtomography set is presented in Fig. 1. Its major part is an X-ray source which is usually an X-ray tube, which consists of two electrodes: an anode and a cathode, built of high atomic weight material. The $\mathrm{X}$-ray radiation is pro- duced when a high voltage is applied between the electrodes. The X-ray beam is transmitted through the sample placed on a rotational stage. The images are recorded on the scintillator which consists of a material transforming energy from the incoming particles into the form of light. The scintillator is connected to a charge coupled device (CCD) camera that changes the light into the digital signal. The amount of digital projections depends on the rotation step that is predetermined before performing the scan. The minimum number of radiographs needed for a full reconstruction of the object, provided that the total rotation is $180^{\circ}$, is given by the relation [9]

$$
R=N \pi / 2
$$

where $N$ is the width of the sample in pixels.

Each pixel of the image that is a result of microtomography shows the intensity of the X-ray beam that has not been absorbed. The intensity $I$ of the transmitted X-ray beam, according to Beer's law, verifies the relation

$$
I(x)=I_{0} e^{-\mu x}
$$

where $I$ represents the intensity of the beam that already has passed through the sample, $I_{0}$ is the initial intensity of the beam and $\mu$ is a linear attenuation coefficient of the material equal to

$$
\mu=\sum f_{i} \mu_{i} \rho_{i}
$$

where subscript $i$ denotes an atomic element, $f_{i}$ is the atomic weight of the fraction of element of the material, $\mu_{i}$ represents the mass attenuation coefficient of the beam energy, and $\rho_{i}$ is a density [9]. Beer's law can be used only when the following conditions are fulfilled:

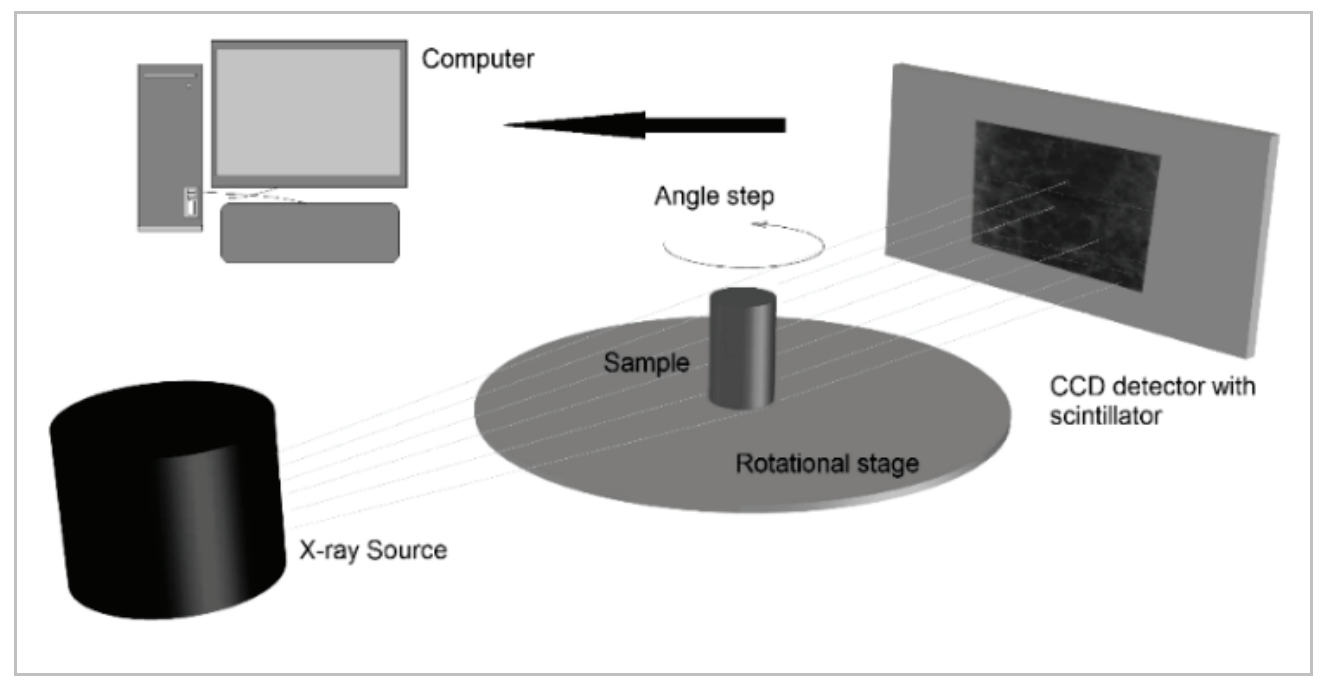

Fig. 1. Scheme of the $\mu \mathrm{CT}$ components 


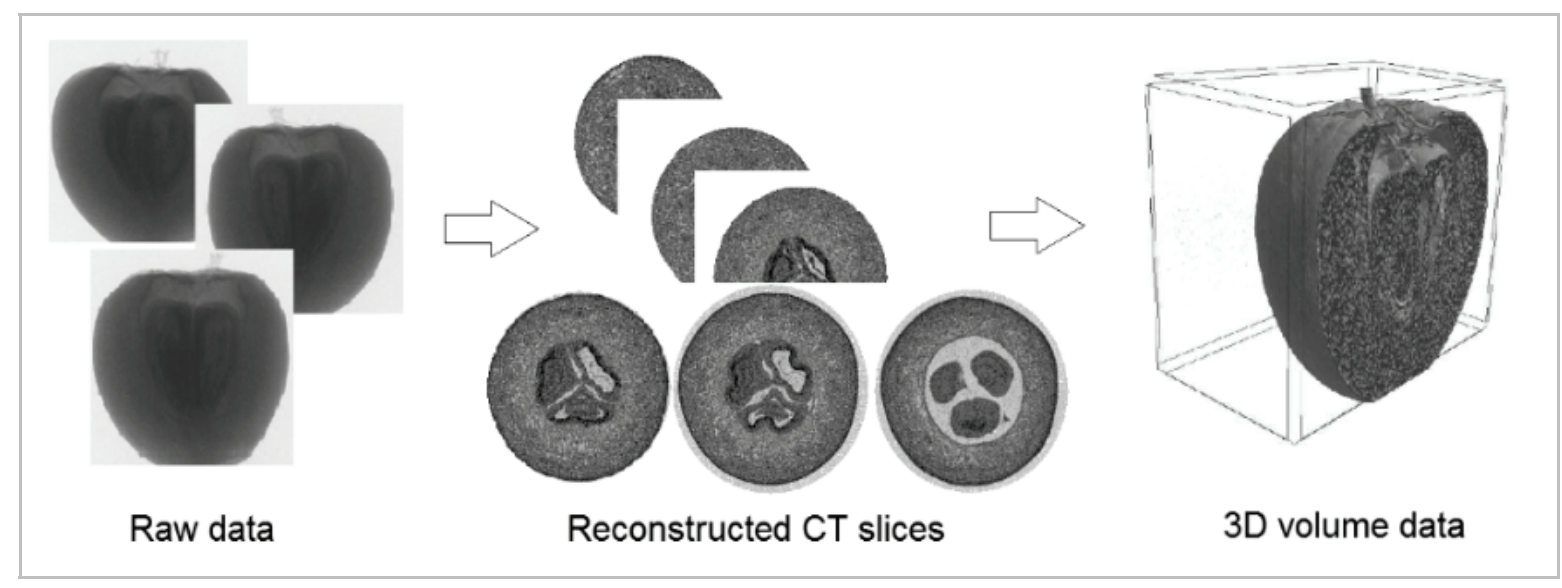

Fig. 2. Micro CT principles

a) there is no diffraction or refraction - X-ray beam is transmitted along the straight lines,

b) X-ray is monochromatic,

c) each material has the characteristic linear attenuation coefficient for a specified X-ray energy [10].

As a result of scanning, the image projections are obtained which are later reconstructed into the set of slices of the sample. They are a series of crosssections on the total height of the material. Later these slices can be used to create a 3D volume data of the material investigated which is used for a volumetric analysis of its properties (Fig. 2).

\section{DETERIORATION OF CONCRETE PROPERTIES DUE TO CARBONATION}

Chemical degradation processes are particularly dangerous for concrete due to its properties. Concrete is a composite material, made of three ingredients: cement, water, aggregate. After the concrete ingredients are mixed, the cement begins to hydrate and the chemical bonding reaction with water occurs. In the presence of water, the silicate and aluminate compounds of Portland cement (Table 1) react and form products of hydration in the form of gel and crystal phases.
The main compounds of the Portland cement - alite and belite - react with water as soon as the paste is prepared. The hydration mechanism of other mineral compounds is similar. The only differences concern the speed of reaction and amounts of $\mathrm{Ca}(\mathrm{OH})_{2}$ created in the hydrolysis reaction [11]. If one assumes that the final product of their hydration is $\mathrm{C}_{3} \mathrm{~S}_{2} \mathrm{H}_{3}(\mathrm{C}-\mathrm{S}-\mathrm{H})$ the overall reactions can be written as [12]

$$
\begin{gathered}
2 \mathrm{C}_{3} \mathrm{~S}+6 \mathrm{H} \rightarrow \mathrm{C}_{3} \mathrm{~S}_{2} \mathrm{H}_{3}+3 \mathrm{Ca}(\mathrm{OH})_{2} \\
2 \mathrm{C}_{2} \mathrm{~S}+4 \mathrm{H} \rightarrow \mathrm{C}_{3} \mathrm{~S}_{2} \mathrm{H}_{3}+\mathrm{Ca}(\mathrm{OH})_{2}
\end{gathered}
$$

Carbonation is the process that occurs in concrete when calcium compounds, produced in the hydration reaction, react with carbon dioxide $\mathrm{CO}_{2}$ from the atmosphere. It is a controversial process because it produces both beneficial and detrimental effects in concrete. The basic chemical reactions are

$$
\begin{aligned}
\mathrm{CO}_{2}+\mathrm{H}_{2} \mathrm{O} & \rightarrow \mathrm{H}_{2} \mathrm{CO}_{3} \\
\mathrm{H}_{2} \mathrm{CO}_{3}+\mathrm{Ca}(\mathrm{OH})_{2} & \rightarrow \mathrm{CaCO}_{3}+2 \mathrm{H}_{2} \mathrm{O}
\end{aligned}
$$

Firstly, carbon dioxide reacts with the water in the pores of the material, forming the carbonic acid. Next, the carbonic acid reacts with calcium hydroxide creating calcium carbonate. The main property of the carbonation process is that it reduces the $\mathrm{pH}$ of concrete, which is shown as follows

Compounds of Portland cement

\begin{tabular}{|l|c|c|c|c|}
\hline \multicolumn{1}{|c|}{ Compound name } & Chemical formula & Oxide formula & Notation & Mineral name \\
\hline Tricalcium silicate & $\mathrm{Ca}_{3} \mathrm{SiO}_{5}$ & $3 \mathrm{CaO} \cdot \mathrm{SiO}_{2}$ & $\mathrm{C}_{3} \mathrm{~S}$ & Alite \\
\hline Dicalcium silicate & $\mathrm{Ca}_{2} \mathrm{SiO}_{4}$ & $2 \mathrm{CaO} \cdot \mathrm{SiO}_{2}$ & $\mathrm{C}_{2} \mathrm{~S}$ & Belite \\
\hline Tricalcium aluminate & $\mathrm{Ca}_{3} \mathrm{Al}_{2} \mathrm{O}_{6}$ & $3 \mathrm{CaO} \cdot \mathrm{Al}_{2} \mathrm{O}_{3}$ & $\mathrm{C}_{3} \mathrm{~A}$ & Aluminate \\
\hline Tetracalcium aluminoferrite & $\mathrm{Ca}_{2} \mathrm{AlFeO}_{5}$ & $4 \mathrm{CaO} \cdot \mathrm{Al}_{2} \mathrm{O}_{3} \cdot \mathrm{Fe}_{2} \mathrm{O}_{3}$ & $\mathrm{C}_{4} \mathrm{AF}$ & Ferrite \\
\hline
\end{tabular}




$$
\begin{gathered}
\mathrm{H}_{2} \mathrm{O}+\mathrm{CO}_{2}=\mathrm{HCO}_{3}^{-}+\mathrm{H}^{+} \\
\mathrm{HCO}_{3}^{-}=\mathrm{CO}_{3}^{2-}+\mathrm{H}^{-} \\
\mathrm{Ca}(\mathrm{OH})_{2}+2 \mathrm{H}^{+}+\mathrm{CO}_{3}^{2-}=\mathrm{CaCO}_{3}+2 \mathrm{H}_{2} \mathrm{O}
\end{gathered}
$$

The pure carbonation does not cause any direct damage to the concrete structure. It densifies the cement paste and locally, as a consequence, increases its strength. However, the consequences of this process are dangerous to the material. The major threat is the aforementioned $\mathrm{pH}$ reduction of the fluid in the pores of the cement matrix. When the whole $\mathrm{Ca}(\mathrm{OH})_{2}$ is carbonated the $\mathrm{pH}$ is reduced even to 8 . This process is particularly dangerous for the reinforcement steel in concrete. Moreover, tricky and complex are the results of the coexistence of carbonation and other destructive phenomena in concrete, the determination of which is the aim of this study.

\section{IDENTIFICATION OF CARBONATION ZONE}

A cylindrical concrete sample of the diameter of $5 \mathrm{~cm}$ and height $10.1 \mathrm{~cm}$ has been examined. The sample was extracted as a core from the wall of the city sewage system canal. The analyzed concrete has been subjected to the diverse aggressive environmental conditions including carbonation and sulfate attack. The mineral composition of the concrete is not known, however it can be notified that it was made of Portland cement.

\subsection{CHEMICAL IDENTIFICATION}

In order to estimate roughly the range of the carbonation depth in the sample, firstly the chemical identification has been implemented. The most popular and commonly used chemical indicator of the carbonation zone is phenolphthalein, which is a chemical compound that turns colorless in acidic solutions and pink in basic ones. Application of phenolphthalein in concrete shows a pink color in the uncarbonated part with free $\mathrm{Ca}(\mathrm{OH})_{2}$ demonstrating alkalinity in this area. On the contrary, the carbonated zone remains unchanged which indicates the acidic environment of this part of the concrete. However, the phenolphthalein test is known to show some significant limitations. It has to be acknowledged that in practice phenolphthalein does not indicate the carbonation itself but the $\mathrm{pH}$ of the material - the pink color occurs when the $\mathrm{pH}$ is higher than 9.5. This fact implies that any kind of acidic gases, including the carbonation effect, is indicated in the identical way [1]. Therefore, phenolphthalein should be used with caution and should be considered as rough estimation of the carbonation depth.

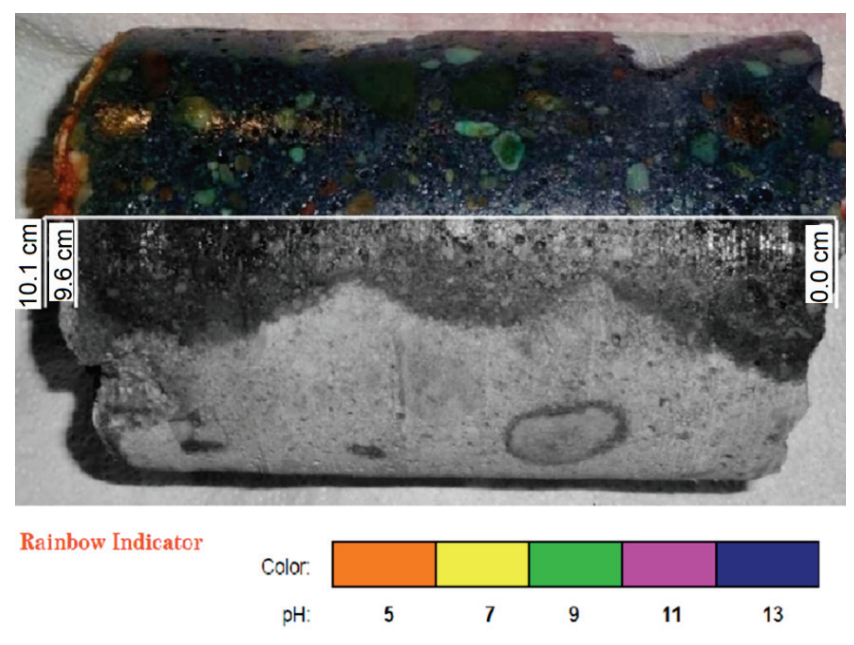

Fig. 3. Carbonation zone identification using chemical indicator

Moreover, there are other, more sophisticated, chemical indicators that are applied for the carbonation zone evaluation. One of them is Rainbow Indicator produced by the company German Instruments $\mathrm{A} / \mathrm{S}$. It operates on a wider range of colors assigned for particular $\mathrm{pH}$ value. This fact allows the carbonated depth of the material to be identified with higher precision. The above-mentioned chemical indicator has been applied for the sample investigated and the results of the experiment are shown in Fig. 3. The carbonation zone has been estimated to be about $0.5 \mathrm{~cm}$ in depth.

\subsection{X-RAY MICRO CT IMAGING}

In order to visualize the concrete microstructure, the sample was scanned with X-ray microtomography. The high resolution Skyscan 1172 system has been used with $11 \mathrm{Mp} \mathrm{X}$-ray camera. Image processing and $3 \mathrm{D}$ reconstruction as well as data analysis have been performed with the use of software (NRecon, DataViewer, CTAn, CTVox) provided by the producer of the equipment.

First scanning was conducted with the medium resolution (2000 px) as a test scan to determine the best scanning and reconstruction parameters. The parameters applied for the scanning were as follows:

- camera resolution $-9 \mu \mathrm{m}$, 
- filter: aluminum + copper $(\mathrm{Al}+\mathrm{Cu})$,

- source voltage $-100 \mathrm{kV}$,

- source current $-100 \mu \mathrm{A}$,

- rotation angle $-0.12^{\circ}$.

The achieved resolution of the images was $13.53 \mu \mathrm{m}$ per 1 pixel. After scanning, the images were processed in the reconstruction software NRecon to reconstruct cross-section images from tomography projection images. The algorithm implemented is the Feldkamp algorithm [13]. To reduce the noise, high smoothing and ring artifact correction functions have been implemented.

The final results were initially confusing and inconsistent. The scanned images of the carbonated and uncarbonated layer did not present any major differences (Fig. 4). It was hard to distinguish the area where the corrosion of concrete occurred. Furthermore, the parameters of the sample were measured in the software and compared for the upper (known to be carbonated) layer and the lower one. The porosity for the upper layer was found to be $0.55 \%$ and for the lower layer $-0.84 \%$. The results showed that there was no significant difference in porosity for each layer, which was surprising.

The preliminary conclusion based on observations and analysis of the results was that the resolution of the scanning was not acceptable and led to the false output. Nonetheless, firstly in order to check the details of the microstructure, the images were zoomed in and just a piece of the sample was saved as a sequence of bit maps for further investigation.

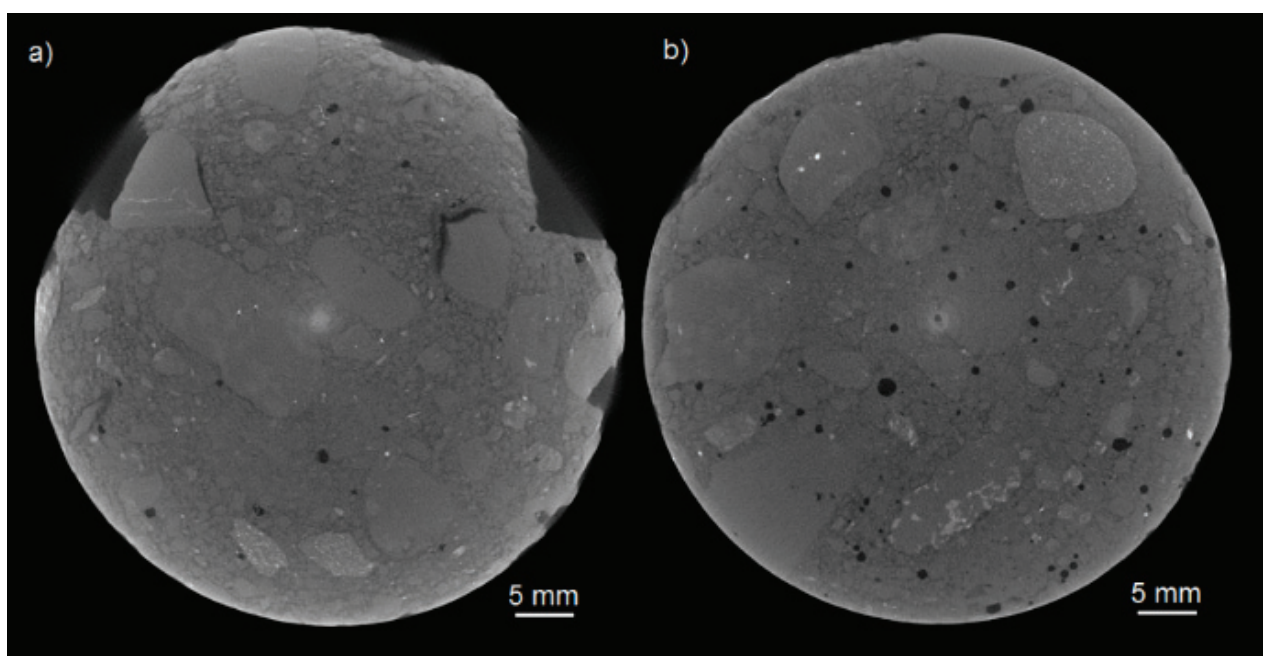

Fig. 4. The images of the cross-sections of the concrete after first scanning: (a) upper layer, (b) lower layer

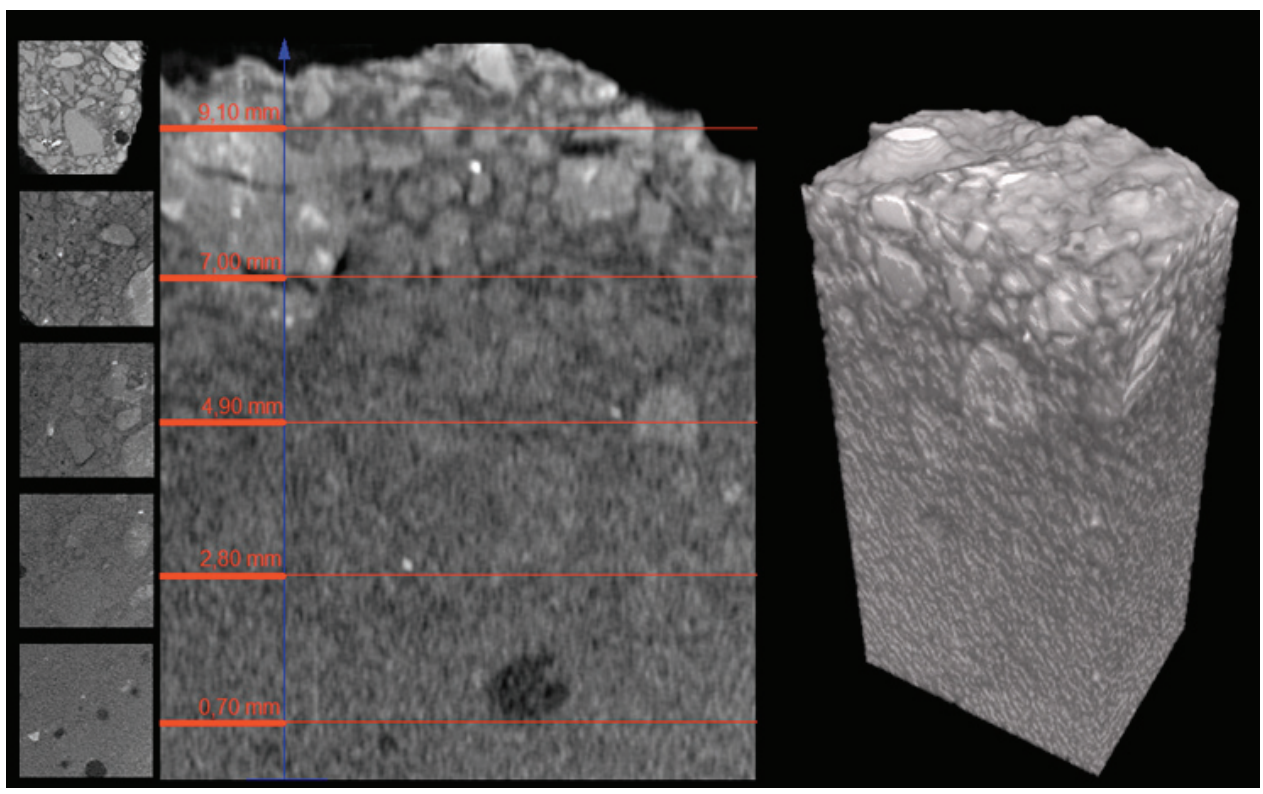

Fig. 5. Cross-sections of the sample at different heights and 3D reconstruction 


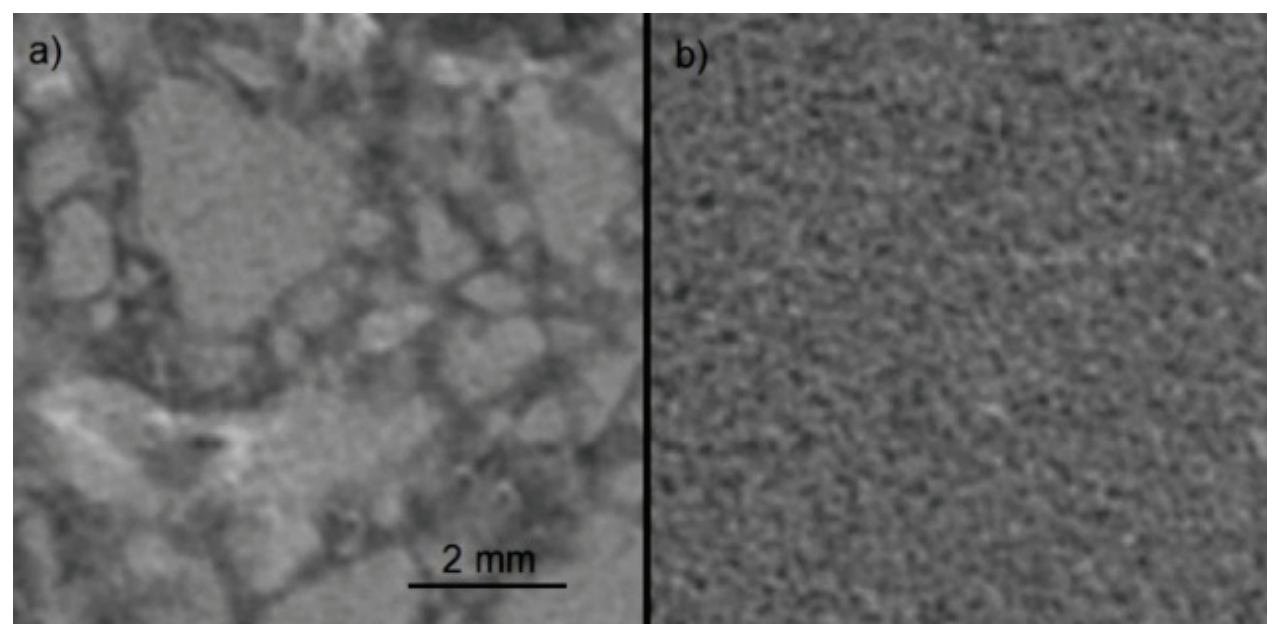

Fig. 6. (a) Upper (corroded) layer of the sample, (b) lower layer of the sample

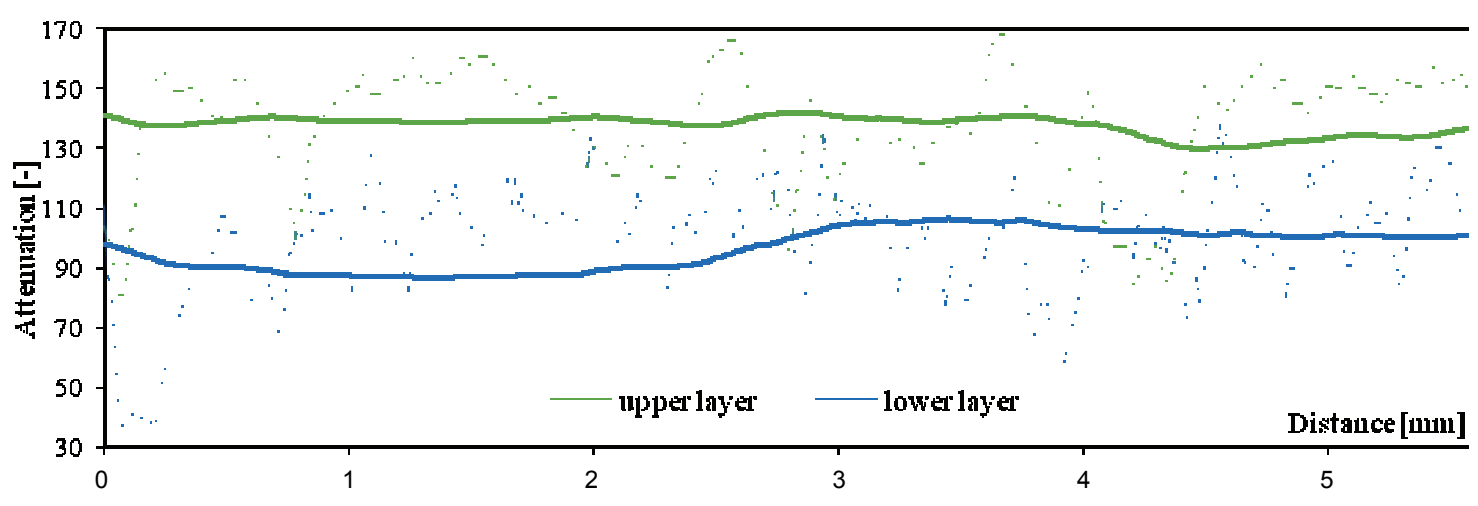

Fig. 7. Attenuation curves for the upper and lower layers of the sample

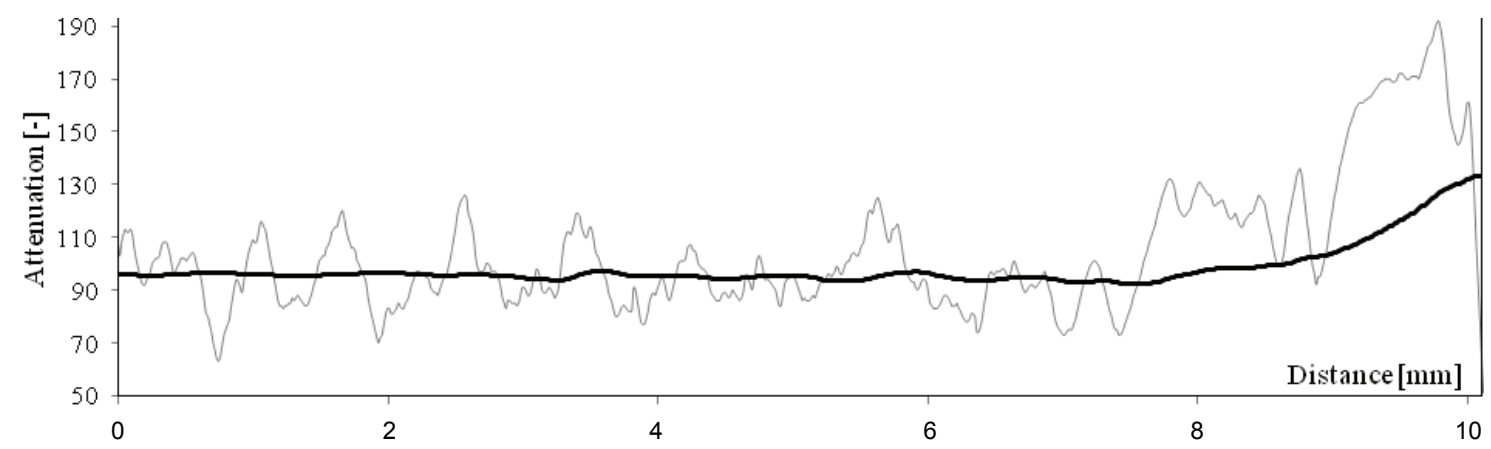

Fig. 8. Attenuation curve on the height of the sample after first scanning

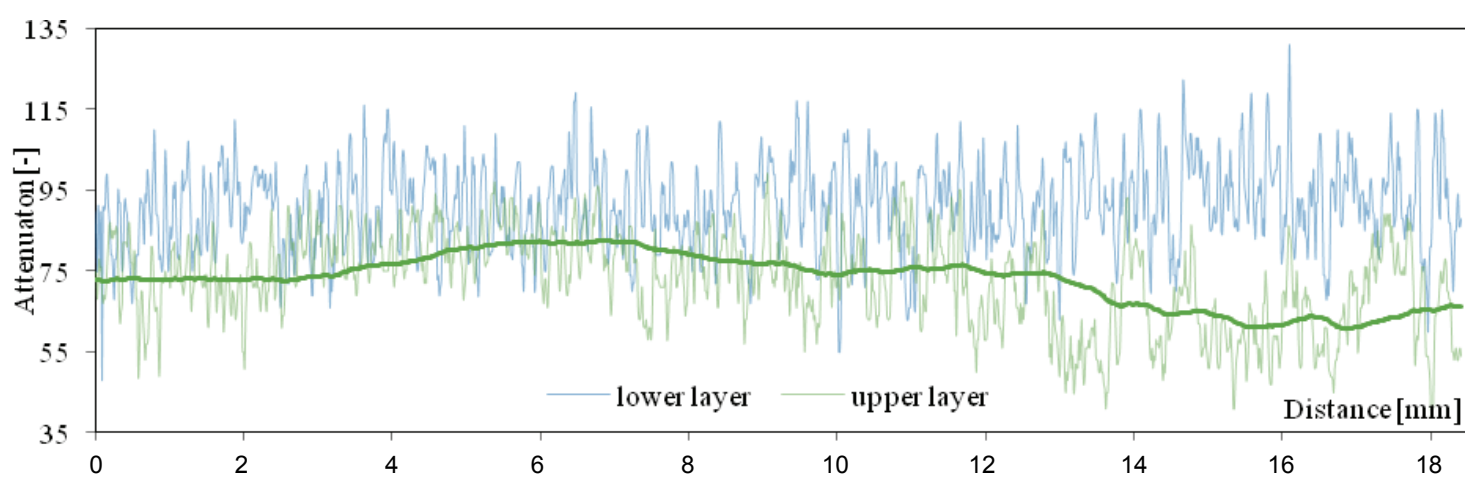

Fig. 9. Attenuation curves of the lower and upper layers after second scanning 
As can be seen from Figs. 5 and 6, the images differ from the previous results. The grey values on the $2 \mathrm{D}$ cross-sections of the sample correspond to the attenuation coefficient which is proportional to the density of the material. The lighter pixels resemble the areas of higher density whereas dark pixels indicate low density areas. It can be clearly seen in Fig. 5 that the density of the concrete increases with height. The upper regions of the sample are almost white, while deeper layers are distinctly darker. As was mentioned earlier, the carbonated concrete tends to have higher density than the uncarbonated one. Therefore, obtained results correspond to this thesis. Additionally, one may easily notice clear changes in microstructure on the upper and lower cross-sectional images of the sample. The matrix (hydrated cement) has changed and it forms irregularly shaped clusters with discontinuities, which indicates that its chemical composition is different than before corrosion processes.

The diversity of microstructure as well as the attenuation coefficient changes are clearly visible on the absorption curves shown in Fig. 7. Density is proportional to the absorption curve thus one can see the rise of the absorption in the direction of the carbonated layer (Fig. 8).

After analysis of preliminary results, the second scanning was made at higher resolution in order to obtain details of the microstructure and to achieve more precise results. Additional scanning was performed according to the following parameters:

- camera resolution $-9 \mu \mathrm{m}$,

- filter: aluminum + copper $(\mathrm{Al}+\mathrm{Cu})$,

- source voltage $-100 \mathrm{kV}$,

- source current $-78 \mu \mathrm{A}$,

- rotation angle $-0.15^{\circ}$.

The achieved resolution of the images was $6.77 \mu \mathrm{m}$ per 1 pixel, so it was twice better than the previous one. This was executed by scanning only a part of the sample, twice smaller than the previous one. The images were processed similarly to the ones before. Additionally, during reconstruction, the misalignment functions had to be used in order to compensate

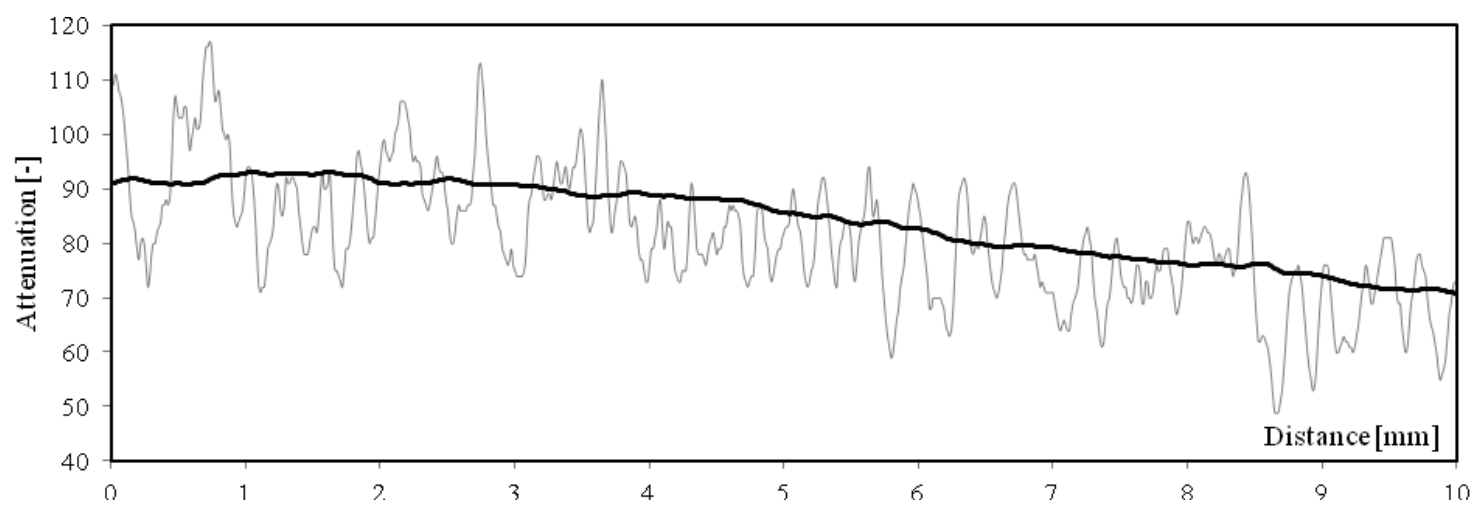

Fig. 10. Attenuation curve on the height of the sample after second scanning

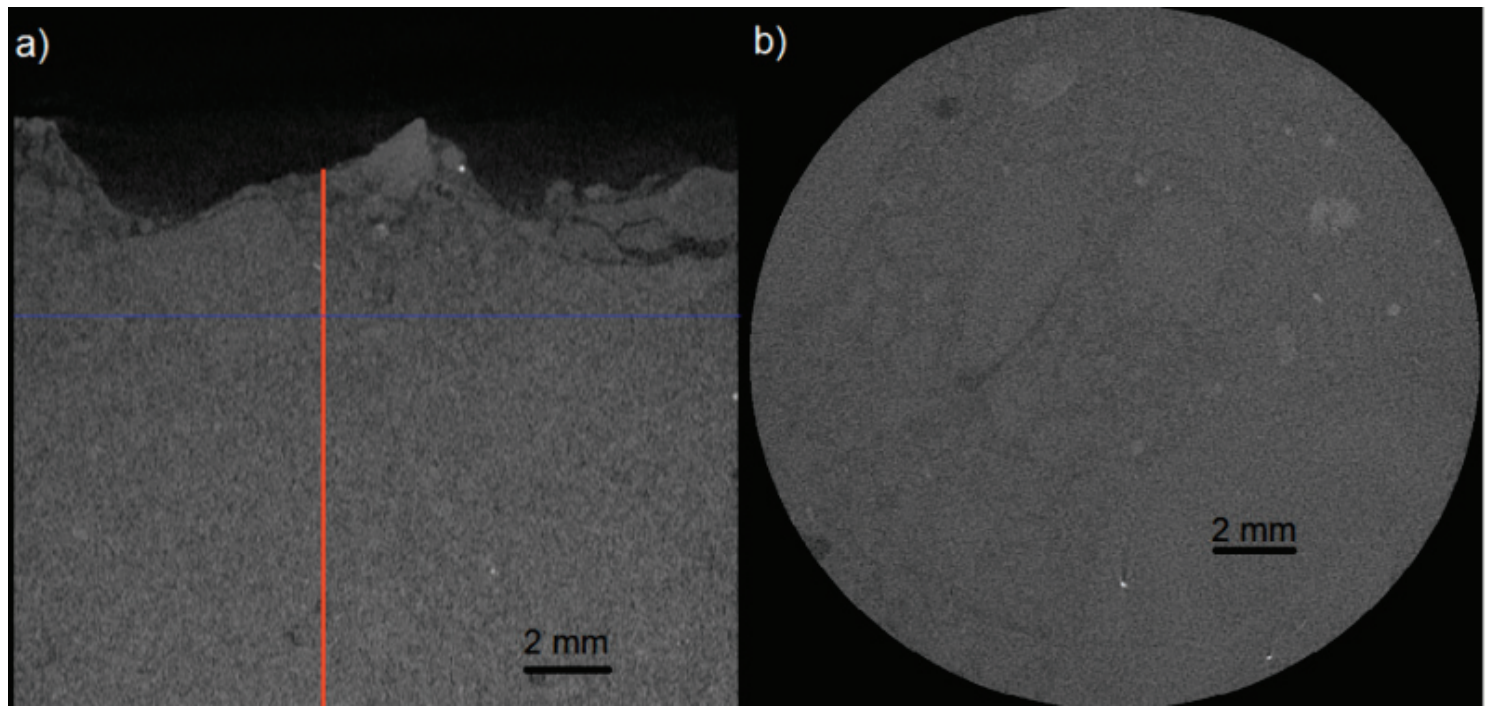

Fig. 11. Results of the final scanning: (a) coronal cross-sections, (b) transaxial cross-section 
possible "displacement" of the images during acquisition.

As a result of the experiment, similar images were achieved to the ones before. However, the carbonation profile looks differently. There is no attenuation curve increase with the height of the sample (Fig. 10). However, one can notice evidently distinguishable micro cracking on the top of sample (corroded layer) (Fig. 11). As Han et al. observed in their experiment [14], the progressing carbonation process results in the final loss of density of the structure due to the occurrence of the cracking.

The cracking is also the main reason of the problematic nature of the carbonation. In the situation investigated in this paper, the sample had been subjected to the harsh environmental conditions for decades and not only to carbon dioxide but also to other chemical compounds. The microcracks presumably appeared after leaching. The carbonated material subjected to other chemical processes was carried downward (eluviated) and probably was redeposited (illuviated) in the lower layer. This resulted in a porous upper layer with lots of microcracks and dense, compact lower layer. The images obtained with the high resolution test prove this theory. This can also be visible on the attenuation curves (Fig. 9). Due to the lower density, one can see a decrease of absorption in the direction of the corroded layer.

\section{CONCLUSIONS}

In this study, a new method is presented to determine the carbonation depth of concrete. An X-ray microtomography system has been used in order to investigate the changes in the microstructure of the material subjected to deteriorating processes. Different sets of scanning parameters were used to obtain the images of the sample tested. The results showed that depending on the $\mu \mathrm{CT}$ parameters, a diverse set of images is acquired. The scanning resolution vastly affects the quality of the images and significantly influences the final outcome of the study. From the images obtained, the information about material density and absorption of the X-ray radiation can be gathered. The attenuation curves were used to compare the microstructural images of concrete on different levels of height of the sample to analyze the carbonation profile of the material.

The results of the tests lead to the conclusion that $\mathrm{X}$-ray computed microtomography is a useful tool for analyzing concrete microstructural behavior due to deterioration mechanisms. In the previous decades, $\mu \mathrm{CT}$ has not been a popular testing method in civil engineering, even though it was widely applied in other areas such as medicine. The experiment, that was the topic of this paper, demonstrated that this technique has a strong potential to gain a widespread popularity in various research fields due to its nondestructive character and high computational power. Nonetheless, the method needs some improvement to become more effective in the area of building materials such as concrete. Upon further improvement, the acquired data will enhance the understanding of durability behavior of concrete structure.

\section{REFERENCES}

[1] Villain G., Theiry M., Platret G., Measurement methods of carbonation profiles in concrete: thermogravimetry, chemical analysis and gammadensimetry, Cement and Concrete Research, 2007, Vol. 37, 1182-1192.

[2] Lo Y., LEE H.M., Curing effects on carbonation of concrete using a phenolphthalein indicator and Fourier-transform infrared spectroscopy, Building and Environment, 2002, Vol. 37, 507-514.

[3] Chang C.-F., Chen J.-W., The experimental investigation of concrete carbonation depth, Cement and Concrete Research, 2006, Vol. 36, 1760-1767.

[4] CNudde V., Boone M.N., High-resolution X-ray computed tomography in geosciences: A review of the current technology and applications, Earth-Science Review, 2013, Vol. 123, $1-17$.

[5] RADON J., Über die Bestimmung von Funktionen durch ihre Integralwerte längs bestimmter Mannigfaltigkeiten, Ber. Verb. Sächs. Akad. Wiss. Leipzig Math.-Nat. K1., 1917, Vol. 69, 262-277.

[6] CORMACK A.M., Representation of a function by its line integrals with some radiological applications, J. Appl. Phys., 1963, Vol. 34, 2722-2727,

[7] CORMACK A.M., Representation of a function by its line integrals with some radiological applications II, J. Appl. Phys., 1964, Vol. 35, 2908-2913.

[8] Hounsfield G.M., Computerized traverse axial scanning (tomography): Part I. Description of system, British Journal of Radiology, 1973, Vol. 46, 1016-1022.

[9] Monteiro P.J.M., KirchineiM A.P., Chae S., Fischer P., Macdowell A.A., Schaible E., WenK H.R., Characterizing the nano and micro structure of concrete to improve its durability, Cement and Concrete Research, 2009, Vol. 31, 577-584.

[10] EPSTEIN C.L., Introduction to Mathematics of Medical Imaging: Chapter 3. A basic model for tomography, SIAM, USA, 2003.

[11] KIERNOŻYCKI W., Betonowe konstrukcje masywne, SPC, Kraków, 2003.

[12] Neville A., Properties of concrete, Pearson Education Ltd., England, 1996.

[13] FeldKamp L.A., Davis L.C., Kress J.W., Practical conebeam algorithm, Journal of Optical Society of America, 1984, Vol. 1, No. 6, 612-619.

[14] Han J., Sun W., PAN G., X-ray microtomography of the carbonation front shape evolution of the cement mortar and modeling of accelerated carbonation reaction, Journal of Wuhan University of Technology-Mater. Sci. Ed., 2013, Vol. 28, No. 2, 303-308. 